\title{
Colibacillosis in calves: A review of literature
}

\author{
Bashahun, G. M.* and Amina A. \\ Jimma University, College of Agriculture and Veterinary Medicine. School of Veterinary Medicine, Jimma, P. O. Box 307, \\ Ethiopia. \\ *Corresponding author. Email: bashahung@gmail.com. Tel: +251 917307139. Fax: +25147 1110935.
}

Copyright $@ 2017$ Bashahun and Amina. This article remains permanently open access under the terms of the Creative Commons Attribution License $\underline{4.0}$, which permits unrestricted use, distribution, and reproduction in any medium, provided the original work is properly cited.

Received 27th January 2017; Accepted 2nd March, 2017

\begin{abstract}
Colibacillosis is considered as one of the most important problems faced in livestock production, causing great economic losses. Calves become exposed to pathogenic E. coli in the environment when other infected or carrier calves and cows shed the bacteria in the feces. Diagnosing of $E$. coli infection in calves depends on an accurate history, clinical signs, culture of internal organs for bacteria, and serotyping of the organism. This disease requires an immediate response, centered on isolation and rehydration therapy. Parental antibiotics can be useful if given early, but not without rehydration therapy. Prevalence of Colibacillosis varies from 5.4 to $100 \%$, and it is roughly estimated that a calf mortality associated with Colibacillosis of $20 \%$ may reduce net profit to $40 \%$. Thus, control and prevention measures should be conducted through the use of dam vaccination before calving, improve hygiene around calving and proper colostrum administration.
\end{abstract}

Key words: Colibacillosis, calves, Escherchia coli, economic loss, hygiene.

\section{INTRODUCTION}

Colibacillosis also known as: E. coli infection, enterotoxigenic E. coli (ETEC) or Septicaemic Colibacillosis. Various serotypes of enterotoxigenic E. coli can cause either diarrhoea or septicaemia in very young calves (Kang et al., 2004; Gruenberg, 2014). Septicemic colibacillosis is a major cause of early calf deaths. The condition is often fatal or leads to post-septicaemic infections that are often non-responsive to treatment. If an outbreak occurs, every effort should be made to isolate the affected calves immediately. ETEC cause diarrhoea in very young calves, less than 3 to 4 days of age (typically less than 48 hours of age). Calves are depressed, do not drink or suckle, become dehydrated, and die rapidly. Very profuse and watery diarrhoea is typical of ETEC scours.

$E$. coli is widely distributed in nature, being present in soil, surface water, animal and human feces. E. coli produces septicemia and diarrhea in a wide range of hosts including man, avian and animals. Calves are the most vulnerable to $E$. coli infection. Two age groups appear to be of calves of 1 to 3 days of age and of 3 to 8 weeks of old are more susceptible. Symptoms include diarrhea, a rise in body temperature, general weakness, dehydrated and lack of appetite. These symptoms are soon followed by coma and death within a few hours (Radostitis et al.,
2000).

Colibacillosis (Escherichia coli) has been implicated as a major cause of scours in calves. Many times, this is the only organism identified following routine bacteriologic culturing. Certain E. coli can cause diarrhea. Many different serotypes of $E$. coli have been identified; some cause scours while others do not. E. coli is always present in the intestinal tract and is usually the agent that causes a secondary infection following viral agents or other intestinal irritants. E. coli scours is characterized by diarrhea and progressive dehydration. Death may occur in a few hours before diarrhea develops. The color and consistency of the feces are of little value in making a diagnosis of any type of diarrhea. The course varies from 2 to 4 days, and severity depends on age of the calf when scours starts and on the particular serotype of $E$. coli (Hudson and White, 1982).

Diagnosis depends on an accurate history, clinical signs, and culture of internal organs for bacteria and serotyping of the organism. The location at which the culture from the intestine was taken is also important. Control of $E$. coli scours can be difficult in a severe herd outbreak. All calves should receive colostrum as soon as possible after birth. This helps the calf to resist $E$. coli infection. Early isolation 
and treatment of scours helps to prevent new cases. There are new E. coli cow vaccines now on the market. These vaccines contain the $\mathrm{K} 99$ antigen which should give immunity against many types of $E$. coli. The vaccine is administered six weeks and three weeks prior to calving. The new $E$. coli vaccine is also available in combination with the Rota and Coronavirus vaccine. This vaccination builds high antibody levels in the colostrum, but the calf must get colostrum in the first few hours of life for the vaccine to be effective (Hudson and White, 1982).

Thus, the aim of this review is to evaluate the existing literatures and disseminate appropriate information on calf Colibacillosis.

\section{METHODOLOGY}

On the way to find literatures, an electronic internet searching was carried out via google scholars. Terminologies used to search and access the required data include colibacillosis, colibacillosis in calves, E. coli in calves, calf diarrhea, and prevalence of colibacillosis in Ethiopia. Books and book chapters, short communication reports, case reports, conference abstracts, recognized international organizations reports, country reports and articles were included in this review. In the present report, all relevant literatures related to calf colibacillosis were reviewed properly to prepare this manuscript.

\section{ETIOLOGY}

The bacterium, Escherichia coli, is the primary cause of diarrhea in calves one to two days old. Usually associated with inadequate intake of the mother's colostrum, unhygienic conditions and stress. It may also occur in older calves subjected to stress (HMD, 2010). E. coli is a natural inhabitant of the intestines. However, some types of $E$. coli bacteria are capable of causing disease. The source of infection in an otherwise uninfected herd is usually normal calves and adult cows that serve as reservoirs of infection. These carrier animals can allow the bacteria to persist in a herd by circulating through animals of all ages. The most common route of infection with these pathogenic forms of $E$. coli is ingestion. It is also possible for calves to become infected via the nasopharyngeal mucosa (i.e. inhalation), which can lead to meningitis (infection of the tissues around the brain). Calves become exposed to pathogenic $E$. coli in the environment when other infected or carrier calves and cows shed the bacteria in the feces. The calves become ill when they ingest $E$. coli from contaminated bedding and calf pails, dirty calf pens, diarrheic calves in overcrowded calving grounds, and from the skin of the perineum and udder of the dam (Arsdall, 2011).

The disease is caused by specific invasive serotypes of $E$. coli that possess virulence factors enabling them to cross mucosal surfaces, overcome the bactericidal plasma factors, and produce bacteremia and septicemia. The main determinant of the disease is deficiency of circulating immunoglobulins as the result of a failure in passive transfer of colostral immunoglobulin. Coli septicemia is seen during the first weeks of life, with the highest incidence in animals of 2 to 5 days old. Bacteremia and septicemia in calves and lambs are most commonly associated with $E$ coli and to a lesser extent Salmonella Spp. Approximately $30 \%$ of diarrheic calves with severe systemic clinical signs were found to be bacteremic or septicemic, with $E$. coli the most commonly isolated pathogen from blood cultures (Gruenberg, 2014).

\section{TYPES OF PATHOGENIC E. COLI}

Pathogenic E. coli are divided into two types: Enteropathogenic E. coli and Uropathogenic E. coli. Further pathogenic E. coli are grouped into enterotoxigenic E. coli (ETEC), enteropathogenic E. coli (EPEC), enteroinvasive $E$. coli (EIEC), enteroaggregative $E$. coli $(\mathrm{EAggEC})$ and enterohemorrhagic E. coli (EHEC). Calf diarrhoea is being controlled primarily following the maintenance of strict hygienic and sanitary measures (Radostits et al., 2000).

Enterotoxigenic E. coli attaches to the wall of the small intestine where it releases toxins that cause the body to excrete fluids into the intestine. This results in severe diarrhea within the first three days of life.

Septicemic E. coli invades the blood stream and travels to distant sites in to body including the joints and other organs.

Enterohemorrhagic E. coli and verocytotoxic E. coli produce shiga-like toxin that destroys intestinal microvilli resulting in hemorrhagic diarrhea in calves that are 2-5 weeks' old.

Among E. coli patho-groups, the most common cause of NCD is ETEC stains that produce the K99 (F5) adhesion antigen (E. coli K99+) and heat-stable (STa or STb) and/or heat-labile (LT1 or LT2) enterotoxins (Kaper et al., 2004). The description of a study of the E. coli strains isolated from the sick calves in Smith and Little (1930) study led Wramby to conclude that these strains were mucoid $E$. coli possessing A-type $\mathrm{K}$ antigens. This type of $E$. coli is associated with a specific form of colibacillosis (the enteric-toxemic form) in which tremendous numbers of $E$. coli is found in the small intestine (Gay, 1964).

Systemic colibacillosis occurs frequently in calves, lambs and poultry. Bacteraemic strains of $E$. coli pass through the mucosa of the alimentary or respiratory tract and enter the blood stream where they may cause either (a) a generalized infection (colisepticaemia) or (b) a localized infection such as meningitis and/or arthritis in calves and lambs (Wray and Morris, 1985). This occurs commonly in hypogammaglobulinaemic calves, usually in colostrums deprived animals, but it may also occur in some colostrum-fed animals which have failed to absorb the immunoglobulins. If colostrum is to be effective, it must be ingested within a few hours of birth because little or no absorption occurs after 24 to 36 hours. 


\section{EPIDEMIOLOGY OF THE DISEASE}

Epidemiological studies have shown that many of the human serotypes mentioned above are capable of spreading and actually causing epidemics of diarrhea in hospitals (Gay, 1964). If evidence of this kind were available from field outbreaks of colibacillosis, it would provide convincing evidence of the pathogenicity of certain strains of $E$. coli for calves. Although there are numerous reports of the epidemic and contagious quality of field outbreaks of colibacillosis, there are few in which these observations are confirmed by serological typing. The first studies of an epidemiological nature were conducted on the experimental calves used in the previously mentioned studies of Aschaffenburg et al. (1951). It is probable that the serotype of $E$. coli associated with the enteric form of colibacillosis will be more easily determined by epidemiological studies of outbreaks of calf diarrhea. There is some evidence to suggest that the isolation of a single serotype of $E$. coli from multiple cases of scouring within the same herd would be an indication that it is the causative agent of the diarrhea.

Varying prevalence of $E$. coli has been reported by different studies. For instance, Hemashenpagam et al. (2009) in India (75\%), Joon and Kaura (1993) in India (23\%), Viring et al. (1993) in Sweden (11.5\%), Khan and Khan (1997) in Pakistan (54\%), Steiner et al. (1997) in Germany (42\%), Bendali et al. (1999) in France (20.3\%), Valdivia-Andy et al. (2000) in Mexico (63.7\%), Oporto et al. (2008) in Northern Spain (35.9\%), and Izzo et al. (2011) in Australia (17.4\%), and Pourtaghi et al. (2013) in Iran $(86.7 \%)$. In addition to this other studies reported the prevalence of the disease as $80 \%$ by Awad et al. (1979), $82 \%$ by Haggag and Khaliel (2002), $5.4 \%$ by Azzam et al. (2006), 35.83\% by El-Shehedi et al. (2013) and $63.6 \%$ by Osman et al. (2013). The differences of the prevalence rates among different studies may be due to the ecological differences and management practice as well as hygienic measures (Cho and Yoon, 2014).

\section{TRANSMISSION}

It is assumed that the primary source of the infection is the feces of infected animals, including the healthy dams and neonates, and diarrheic newborn animals, which act as multipliers of the organisms. Invasion occurs primarily through the nasal and oropharyngeal mucosa but can also occur across the intestine or via the umbilicus and umbilical veins. Septicemic strains of $E$ coli produce endotoxin, which results in shock and rapid death. There is a period of subclinical bacteremia that, with virulent strains, is followed by rapid development of septicemia and death from endotoxemic shock. A more prolonged course, with localization of infection, polyarthritis, meningitis, and less commonly uveitis and nephritis, is seen with less virulent strains. Chronic disease also develops in calves that have acquired marginal levels of circulating immunoglobulin. The organism is excreted in nasal and oral secretions, urine, and feces; excretion begins during the preclinical bacteremic stage. Initial infection can be acquired from a contaminated environment. In groups of calves, transmission is by direct nose-to-nose contact, urinary and respiratory aerosols, or as the result of navel sucking or fecal-oral contact (Gruenberg, 2014).

\section{PATHOGENESIS}

The primary harm from scours is loss of water and electrolytes (body salts) in the diarrhea. This loss of water and salts creates dehydration and alteration of the acidbase balance of the bodily fluids. Inflammation of the intestinal lining impairs the calf's ability to digest nutrients, creating weight loss and the potential for hypoglycemia (low blood sugar). If untreated, these changes can be severe enough to result in death. E. coli causes a watery diarrhea and weakness in 1 to 4 days old newborn calves. Death usually occurred within 24 hours due to severe dehydration (Cho et al., 2010). The fimbrial adhesion F5 (K99) promotes the adhesion of bacterial cells to glycoproteins on the epithelial surface of the jejunum and/or ileum, and bacterial enterotoxin also causes damage to the epithelial cells, resulting in fluid secretion and diarrhea (Acres, 1985).

Pathogenicity of $E$. coli strains are due to the presence of one or more virulence factors including invasiveness factors like invasins, heat labile, heat stable enterotoxins, verotoxins and colonization factors or adhesins (Kaper et al., 2004). In addition, the virulence reasons associated with colibacillosis include the possession of large transmissible virulence plasmids, as well as the ability to resist phagocytosis and serum killing. They also include the ability to uptake iron at low extracellular concentrations and, most importantly, the ability to attach and adhere to the host's structures. Age of the host also plays a role in the pathogenicity of $E$. coli types. There are other risk factors that increase the likelihood of a colibacillosis infection as well. The $E$. coli strain, the strength of the host's immune system and exposure time all play a role (Lutful, 2010).

\section{CLINICAL FINDINGS}

Colibacillosis can be detected in livestock by severe diarrhea caused by enteritis, lameness, stunted growth, inactivity, lack of appetite and water consumption, and unresponsiveness. These factors are common signs of the infections listed above, and are all possible indicators of colibacillosis. It is important to note that one infected animal might not express all of these characteristics, or even most of them. If an animal possesses one or more of these factors, it does necessarily have colibacillosis either. These are simply common symptoms of the disease. Colibacillosis signs are nonspecific and vary widely among 
different hosts. Morbidity and mortality are very variable depending on which infection/infections the $E$. coli strain causes in a particular flock of animals (Ahmed et al., 2013; Nolan, 2013).

In the per-acute and acute disease, the clinical course is short ( 3 to 8 hours), and signs are related to development of septic shock. Fever is not prominent, and the rectal temperature may even be subnormal. Listlessness and an early loss of interest in sucking are followed by depression, poor response to external stimuli, collapse, recumbency, cold extremities, and coma. Tachycardia, a weak pulse, and prolonged capillary refill time are seen. The feces are loose and mucoid, but severe diarrhea is not seen in uncomplicated cases. Tremor, hyperesthesia, opisthotonos and convulsions are seen occasionally, but stupor and coma are more common. Mortality approaches $100 \%$. With a more prolonged clinical course, the infection may localize. Polyarthritis, ophthalmitis, omphalophlebitis, and meningitis may occur within the first week of the initial bacteremic phase (Gruenberg, 2014).

Profuse, foul-smelling, yellow-to-white diarrhea, may infect the lungs, navel or joints with affected calves being dull and emaciated and may cause sudden death in calves under two weeks of age due to septicaemia or toxaemia (HMD, 2010). The clinical syndrome believed to be associated with colibacillosis may vary considerably. Calves may be affected with diarrhea for prolonged periods of time, or they may die suddenly with an acute septicemia. There are, however, other diseases of calves which may simulate colibacillosis (i.e., acute septicemias caused by Streptococcus, Diplococcus, Pasteurella and Salmonella spp.). There are also a variety of conditions, both infectious and noninfectious, which may cause diarrhea in young calves. The syndromes associated with colibacillosis have been divided into three forms on clinical and bacteriological grounds and on the grounds of possible pathogenesis (Gay, 1964). First, the colisepticemic form of colibacillosis usually results in the rapid death of the calf and is associated with an $E$. coli bacteremia. Although many strains of $E$. coli have been isolated from cases of colisepticemia, the isolations from the internal organs of a given case are of a single strain in pure culture. Second, the enteric-toxemic form is also associated with the collapse and rapid death of the calf, but it is associated with the proliferation of certain specific strains of $E$. coli in the small intestine. There is no bacteremia, and death is presumably due to a toxemia. This form is probably analogous to that called isocolibacillosis in some earlier publications. Finally, the enteric form is part of the syndrome of the scouring calf. Death may or may not occur depending upon the severity of the physiological derangements produced.

\section{DIAGNOSIS}

The family Enterobacteriaceae is composed of gram- negative rods which may or may not be motile, and it attacks glucose with the production of acid or acid and gas. Nitrates are usually reduced to nitrites. On the basis of further biochemical reactions, the family may be arranged into divisions and then into groups, one of which is $E$. coli. These groups are not distinct, but form dense populations within the family which have certain biochemical properties. Within the E. coli group, the individual strains are identified by serological methods. These serological types can be further divided or classified by biochemical characteristics, phage susceptibility and susceptibility to colicines (Parr et al., 1960; Barry et al., 1962). There are three main antigens of $E$. coli which are used in its identification: 0 or somatic antigens, $\mathrm{K}$ antigens which occur as capsules or microcapsules, and $\mathrm{H}$ or flagella antigens.

No single laboratory parameter is considered reliable for early diagnosis of septicemia. A moderate but significant leukocytosis and neutrophilia are seen early, but leukopenia is more common in severe and advanced cases. A left shift of neutrophils and signs of toxicity of neutrophils as well as hypoglycemia are common findings. Because failure of transfer of passive immunity is the single most important predisposing factor, subnormal serum $\lg G$ and total protein concentrations are common. Subnormal platelet counts are the result of a consumptive coagulopathy. In cases of arthritis, the joint fluid has an increased inflammatory cell count and protein concentration. With meningitis, the CSF shows pleocytosis and an increased protein concentration; organisms may be evident on microscopic examination. Less commonly, other bacteria, including other Enterobacteriaceae, Streptococcuss pp and Pasteurellas pp, produce septicemic disease in young calves. These organisms are more common in sporadic cases than as causes of outbreaks. They produce similar clinical disease but can be differentiated by culture. As with colisepticemia, the primary determinant of these infections is a failure of passive transfer of colostral immunoglobulins (Gruenberg, 2014).

Upon postmortem examination, lesions are nonspecific. However, the small intestine may be filled with fluid and the large intestine may contain yellowish feces. Generally, the diagnosis is based on history and clinical findings, demonstration of a severe deficiency of circulating lgG, serological test and ultimately, demonstration of the organism in blood or tissues; biochemical analyses (Gruenberg, 2014).

\section{Differential diagnosis}

\section{Salmonellosis}

Calves are usually affected at six days of age or older. This age corresponds very closely to the age of the coronavirus infection. Clinical signs associated with salmonella infection include diarrhea, blood and fibrin in the feces, 
depression, and elevated temperature. The disease is more severe in young or debilitated calves. Finding a membrane like coating in the intestine on necropsy is strong presumptive evidence that salmonella might be involved (Hudson and White, 1982).

\section{Rotavirus}

A reo-like virus can cause scours in calves within 24 hours of birth. However, when the infection- is first introduced into the herd, it can affect calves up to 30 days of age or older. Infected calves are severely depressed. There may be a drooling of saliva and profuse watery diarrhea (Hudson and White, 1982). The feces will vary in color from yellow to green. The reo-like virus infection alone causes no diagnostic gross lesions in the intestine, but there is an increased volume of fluid in both the small and large intestine.

\section{Bovine Virus Diarrhea}

The virus of bovine virus diarrhea can cause diarrhea and death in young calves. Diarrhea begins two to three days after exposure and may persist for quite a long time. Ulcers on the tongue, lips, and in the mouth are the usual lesions that can be found in the live calf (Hudson and White, 1982).

\section{Coronavirus}

Diarrhea caused by coronavirus occurs in calves that are over five days of age. At the start of the infection in herd, calves up to six weeks of age may scour. These calves are not as depressed as those infected with rotavirus. Initially, the fecal material may have the same appearance as that caused by rotavirus. As the calf continues to scour for several hours, the fecal material may contain clear mucus that resembles the white of an egg. Diarrhea may continue for several days. Mortality from coronavirus scours ranges from 1 to $25 \%$ (Hudson and White, 1982).

\section{Coccidiosis}

Coccidiosis is caused by one-celled parasites that invade the intestinal tract of animals. There are many species of coccidia. Eimeriazurnii and Eimeriabovis are usually associated with clinical infections in cattle. Coccidiosis has been observed in calves three weeks of age and older, usually following stress, poor sanitation, overcrowding or sudden changes of feed. It often occurs in calves of 7 to 14 days after they are moved from the calving lots onto pasture (Hudson and White, 1982). Occasionally, clinical coccidiosis will be present with bleeding and very few parasites in the fecal material. Death may occur during the acute period or later from secondary complications.

\section{Cryptosporidium}

Cryptosporidium is a protozoan parasite that is much smaller than coccidia. It has the ability to adhere to the cells that line the small intestine and to damage the microvilli. Several reports from researchers and diagnosticians have associated cryptosporidium with outbreaks of calf scours. As a rule, cryptosporidium is detected in combination with coronavirus, rotavirus, and/or E. coli. Calves infected by cryptosporidium (Figure 1) have ranged from 1 to 3 weeks in age (Hudson and White, 1982)

\section{Nutritional cause}

Nutritional in calves can be caused by anything that disrupts this normal habit. A storm, strong wind, or the mother going off hunting for new grass disrupts the normal nursing pattern. When the hungry calf does get an opportunity to nurse, the cow's udder may contain more milk than normal and the calf may overeat resulting in a nutritional scour. Erratic nursing patterns may also be conducive to enterotoxemia. Nutritional scours is usually white scours caused by undigested milk passing through the intestinal tract (Hudson and White, 1982). This type of diarrhea usually presents little problem in treatment. If the affected calves are still active and alert, no treatment is required. If the calf becomes depressed or fails to nurse, it should be treated.

\section{TREATMENT}

This disease requires an immediate response, centered on isolation and rehydration therapy. Parental antibiotics can be useful if given early, but not without rehydration therapy (Constable et al., 1992). Treatment requires aggressive antimicrobial, fluid and anti-inflammatory therapy (Figure 2). Although blood cultures are recommended to retrospectively confirm the diagnosis, antimicrobial therapy must be initiated immediately in any animal suspected of being septic. Because there is no time for sensitivity testing, the initial choice should be a bactericidal drug that has a high probability of efficacy against gramnegative organisms. Administration IV of large volumes of balanced electrolyte solutions over several hours is essential to correct hypovolemia and assure adequate peripheral tissue perfusion; fluids should include glucose to correct hypoglycemia. The beneficial effect of NSAIDs has been attributed to their anti-inflammatory, antipyretic, and analgesic properties. Glucocorticoids have also been proposed to treat septicemia, although their benefits for treatment of sepsis are less well established (Gruenberg, 2014).

\section{CONTROL AND PREVENTION}

Calves that acquire adequate concentrations of 

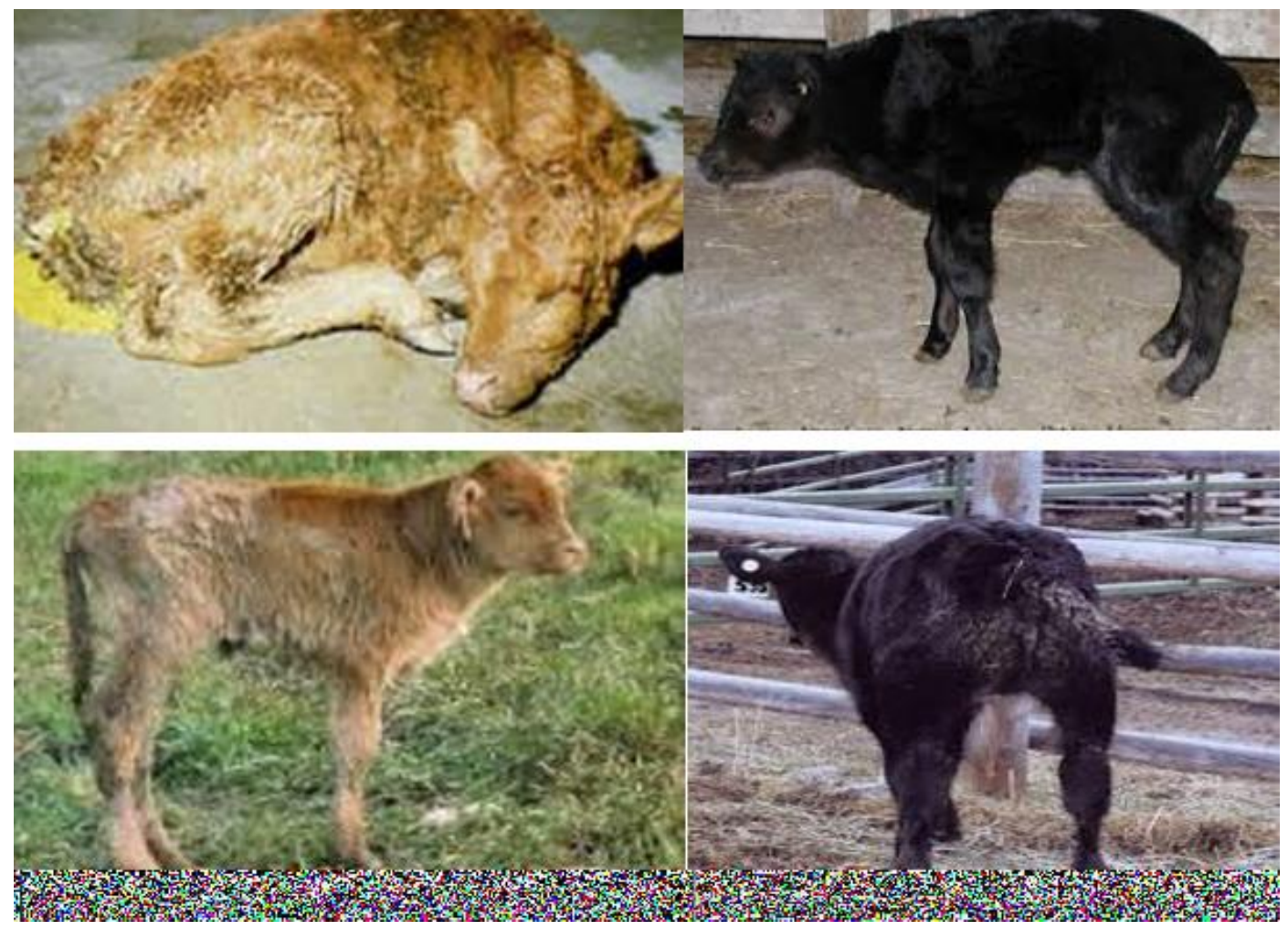

Figure 1. Calves infected by Colibacillosis (adopted from calfology.com/printpdf/2480).
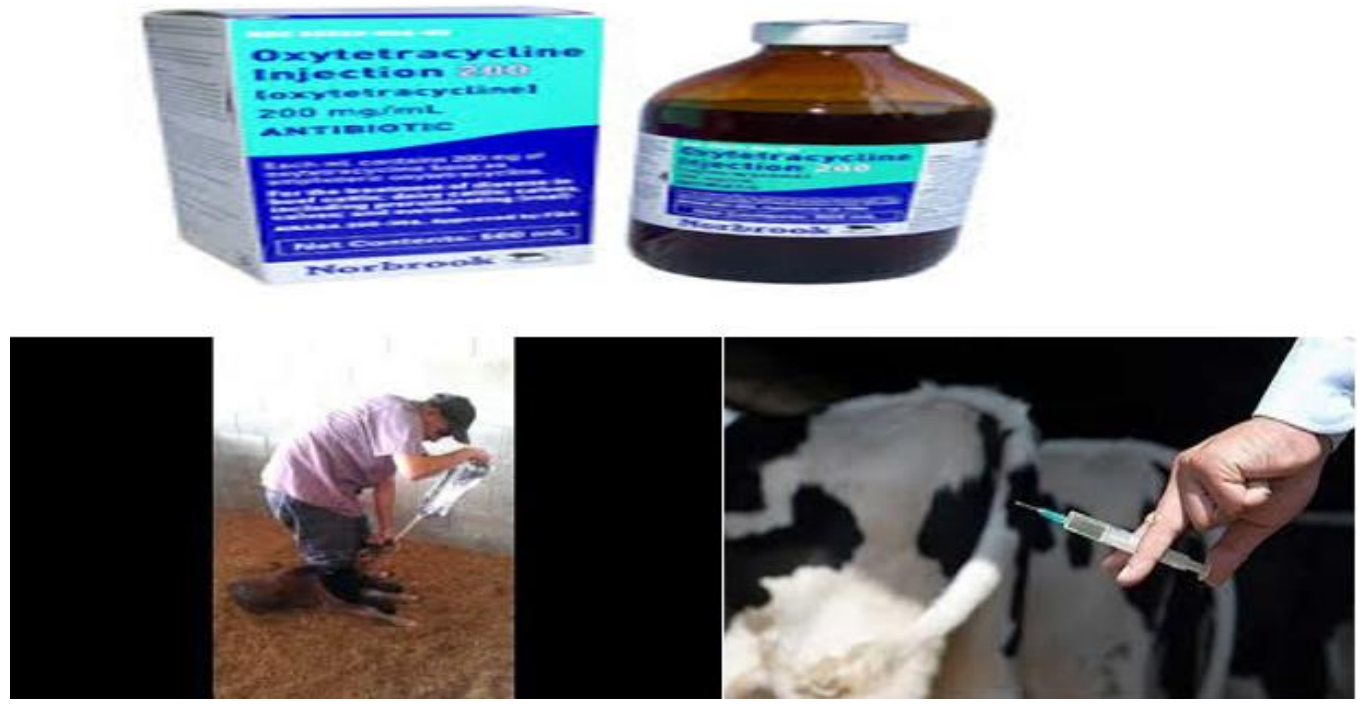

Figure 2. Antimicrobial, fluid, and anti-inflammatory therapy (calfology.com/printpdf/2480).

immunoglobulin from colostrum are resistant to colisepticemia. Therefore, prevention depends primarily on management practices that ensure an adequate and early intake of colostrum. The adequacy of the farm's practice of feeding colostrum should be monitored, and corrective strategies applied as required. In North
American Holstein dairy herds, natural sucking does not guarantee adequate concentrations of circulating immunoglobulins, and calves should be fed 2 to $4 \mathrm{~L}$ of firstmilking colostrum containing a minimal total mass of $100 \mathrm{~g}$ of $\mathrm{lgG}$, using a nipple bottle or an esophageal feeder, within 2 hrs of birth; this is followed by a second feeding at 


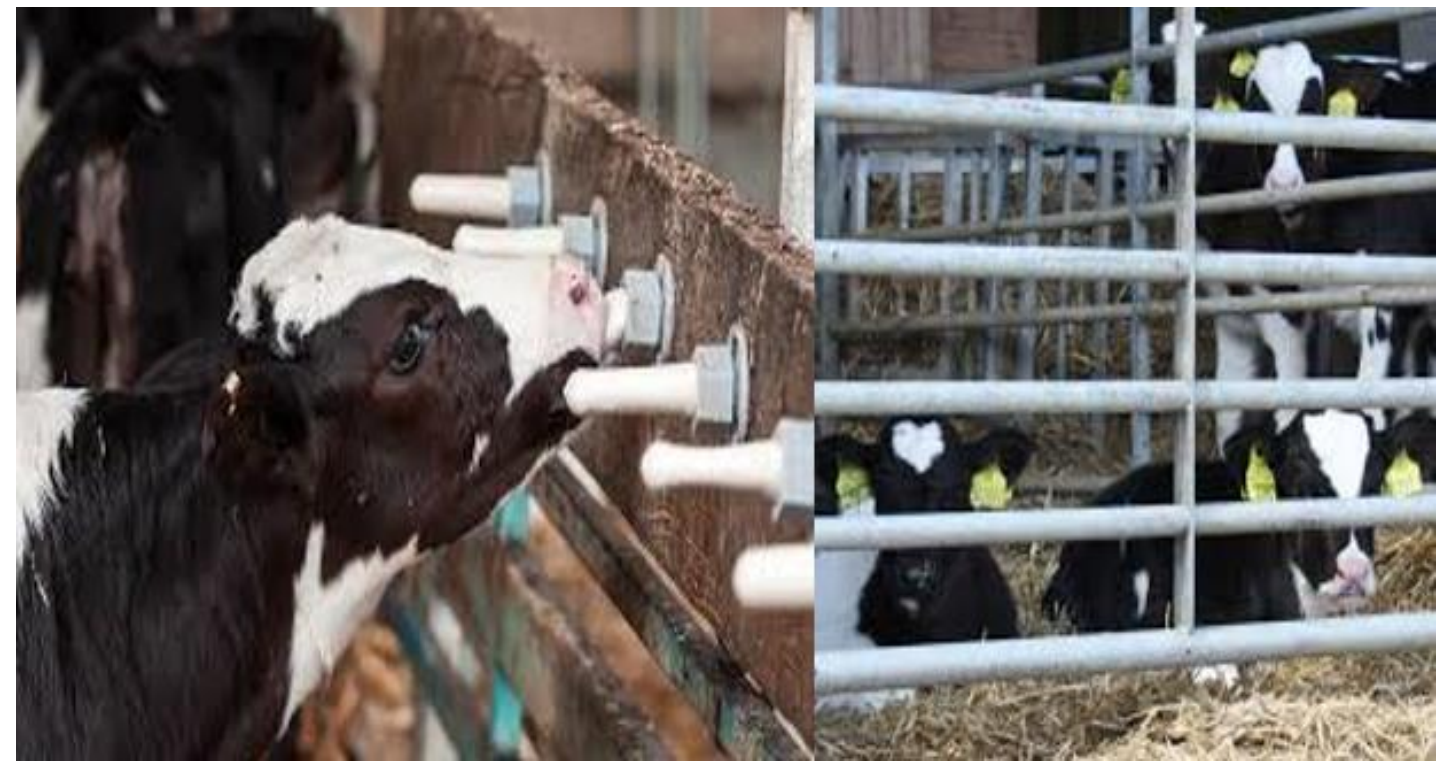

Figure 3. Calves kept in well hygienic pens (adopted from calfology.com/printpdf/2480).

12 hrs. A cow-side immunoassay test can assist in selection of colostrum with adequate immunoglobulin concentration. Although the circulating concentration of immunoglobulin required to protect against colisepticemia is low, high concentrations are desirable to decrease susceptibility to other neonatal infectious diseases (Gruenberg, 2014).

When natural colostrum is not available for a newborn calf, commercial colostrum substitutes containing $25 \mathrm{~g}$ of IgG will provide sufficient immunoglobulin for protection against coli septicemia if fed early in the absorptive period. Plasma containing at least $4 \mathrm{~g}$ and preferably $8 \mathrm{~g}$ of $\lg \mathrm{G}$, administered parenterally, will provide some protection for older calves that have not been fed colostrum and are unable to absorb immunoglobulins from the intestine. Small-volume hyper immune serum is of benefit only when it contains antibody specific to the particular serotype associated with an outbreak. The risk of early infection should be minimized by hygiene in the calving area and disinfection of the navel at birth. To minimize transmission, calves reared indoors should be in separate pens (without contact) or reared in calf hutches (Gruenberg, 2014).

Despite the increased availability of vaccines against ETEC and other pathogens associated with NCD and continued emphasis on optimizing colostral transfer of passive immunity, improved treatment protocols for calf diarrhea are necessary. Although, the administration of intravenous fluids and oral electrolyte solutions plays the main role in treatment, the efficacy of antimicrobial drugs in treating calf diarrhea is argumentative (Constable, 2004). Diarrheic calves are more likely to have failure or partial failure of passive transfer, and so they are more likely to be bacteraemic (Constable, 2004) and this is an additional cause that antimicrobial agents might be indicated in the treatment of calf diarrhea. The type of antibiotic drug should better be selected on the basis of its sensitivity, which could be detected by laboratory examination, and the antimicrobial treatment of diarrheic calves should therefore be focused against bacteria in the two sites of infection: the small intestine and the blood (Constable, 2004).

Ensuring a clean environment for calving minimizes exposure to potential pathogens such as E. coli (Figure 3). The passive immunity acquired from the colostrum and absorbed into the circulation from the gut is the calf's main defense mechanism against $E$. coli diarrhea. Inadequate amounts of antibodies in the colostrum, inadequate intake of the colostrum and inadequate absorption of antibodies from the gut render very young calves susceptible to infection (Groutides and Michell, 1990). Additionally, among calves aged 1 to 4 months old, carriage of VTEC E. coli 157 was reduced if the calf had suckled colostrum from the mother or if the calf had stayed more than two days with the mother after calving. For herd where a known infection is present an improvement in colostrum feeding in the first 6-9 hours of life and dam immunization against ETEC E. coli F5 (K99) adhesin (Rotavec Corona, Schering Plough Animal Health, Lactovac, Zoetis Animal Health, Trivacton 6, Merial Animal Health) are the main ways of controlling disease.

\section{ECONOMIC IMPORTANCE OF THE DISEASE}

The economic loss occasioned by neonatal disease in young calves has been recognized for many years. It is apparent from postmortem and bacteriological examination of such calves that there are many causes of this loss; 

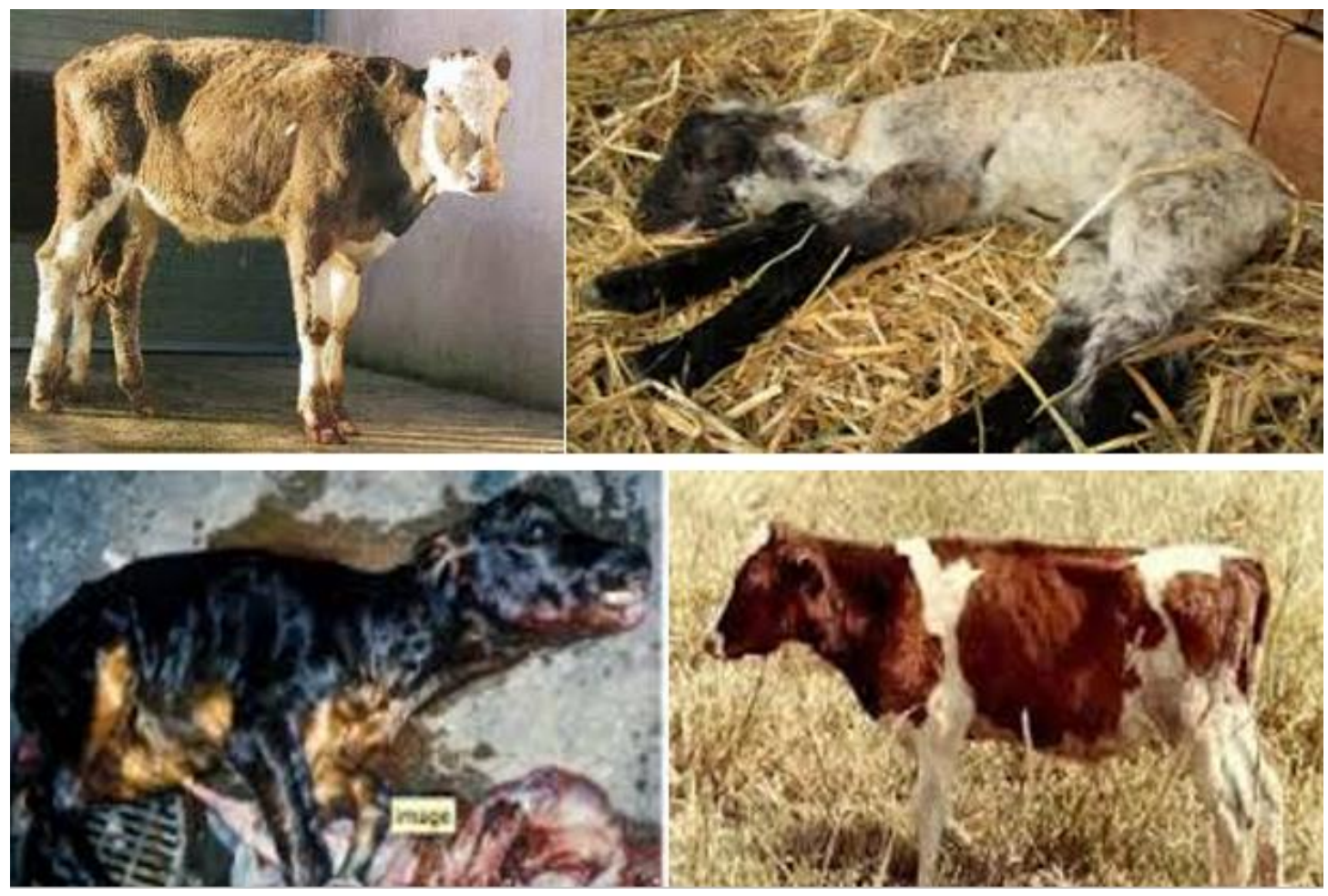

Figure 4. Calf morbidity and mortality resulting from Colibacillosis infection (adopted from calfology.com/printpdf/2480).

however, colibacillosis infection caused by $E$. coli is by far the most common (Linton, 1960). For instance, it is roughly estimated that a calf mortality of $20 \%$ may reduce net profit to $40 \%$ (Blood and Radostitis, 1989). Mortality in neonatal calves has been mostly attributed to infectious agents, such as enteropathogenic E. coli, Salmonella spp. and other viral agents.

Neonatal calf diarrhea is one of the most common diseases in young animals, causing huge economic and productivity losses to bovine industry worldwide (Cho and Yoon, 2014). Among bacteria, ETEC is the most economically important pathogen (Achá et al., 2004), although other bacteria have also been identified as causes of enteric disease. Gunn (2003) reported that the losses due to an occurrence of the disease include: calf death (Figure 4) - which is effectively the loss of income from a cow for the year, cost of treatment of the calf, including the time taken, which can be significant in a paddock situation, impact on growth rate and possible lower weaning weight, culling cost of the dam (in most situations she is likely to be culled because she does not have a calf at foot at weaning/marking), loss of genetic potential from the calf and the dam and decreases capacity to improve and maintain the herd. In general, the published data shown that, diseases of the new born calf mortality are the major causes of economic losses in livestock production (Singh et al., 2009). High numbers of calves usually affected within a herd and the cost of treatment of diseased calves, long-term ill-thrift in chronically affected calves and the cost of losing potential replacement heifer calves (HMD, 2010).

\section{Zoonotic Importance}

Several of the agents that produce diarrhea in calves can also produce diarrheal disease in people. These organisms are commonly present as subclinical infections in the gut of calves and lambs; immune compromised people should avoid contact with young ruminants and possibly all farm animals (Radostits et al., 1994). Cattle, including calves, are one of the reservoirs for the verotoxic E. coli serotype $0157: \mathrm{H} 7$ that is associated with human hemorrhagic colitis and the hemolytic uremic syndrome. Infection in people is usually acquired by consumption of contaminated food, but the infective dose is low, and the possibility of infection by direct contact exists (Smith, 2002).

Other verotoxic $E$. coli associated with human disease can also be isolated from the feces of healthy cattle. Human disease from infection with enteric livestock pathogens has occurred after seemingly trivial contact associated with visits to livestock fairs, petting zoos, and farm educational tours. Hand cleansing and disinfection should be a component of these visits (Carter and Changapa, 1989). 


\section{CONCLUSION}

Colibacillosis is considered as one of the most important problems faced in livestock production, causing great economic losses. Prevalence of Colibacillosis varies from 5.4 to $100 \%$, and it is roughly estimated that a calf mortality associated with Colibacillosis of $20 \%$ may reduce net profit to $40 \%$. Thus, effective control and prevention measures should be done through the use of dam vaccination before calving, improve hygiene around calving and proper colostrum administration.

\section{LIMITATIONS}

This review has some limitations; as there is a lack of recent published documents, the old literatures were also reviewed to show relevant information on Colibacillosis in calves.

\section{CONFLICT OF INTEREST}

The authors declare that they have no conflict of interest.

\section{REFERENCES}

Achá, S. J., Kuhn, I., Jonsson, P, Mbazima, G., Katouli, M., \& Mollby, R. S. (2004). Studies on calf diarrhoea in Mozambique: prevalence of bacterial pathogens. Acta Vet. Scand., 45, 2736.

Acres, S. D. (1985). Enterotoxigenic Escherichia coli infections in newborn calves: a review. J. Dairy Sci., 68, 229-56.

Ahmed, M., Youssef, F., \& Rahman, A. (2013). Differentiation between $E$. coli strains causing diarrhea in broiler chicken by using multiplex PCR. Proc. 6th Inter. Conf. Vet. Res. Div., NRC, Cairo, Egypt, Pp. 33-47.

Arsdall, D. V. (2011). E. Colibacillosis. http://calfology.com/library/wiki/e-colibacillosis.

Aschaffenburg, R., Bartlett, S., Kon, S.K., Roy, J. H. B., Walker, D. M., Briggs C., \& Lovell, R. (1951). The nutritive value of colostrum for the calf. IV. The effect of small quantities of colostral whey, dialyzed whey and 'immune lactoglobulins. Brit. J. Nutr., 5, 171-176.

Awad, F. I., Farrag, I., Shawkat, M. E., \& Abeid, M. H. (1979). Studies on enterotoxaemia in young buffalo calves. Egypt J. Vet.Sci., 14(1), 24-9.

Azzam, R. A., Hassan, W. H., Ibrahim, M. A., \& Khaled, M. S. (2006). Prevalence of verocytotoxigenicE. coli O157: H7 in cattle and man in Beni-Sueif Government. Alex J. Vet., 24(1), 111-122.

Barry, G. T., Abbot, V. D., Everhart, D. L., Leffler, R. J., \& Mynant, E. (1962). Relationship of serotype to colicine type in Escherichia coli. Bacteriol. Proc., p. 51.

Bendali, F., Bichet, H., Schelcher, F., \& Sanaa M. (1999). Pattern of diarrhea in new born calves in South west France. Vet. Res., 30, 61-74.

Carter, R., \& Changapa, M. (1989). Essentials of veterinary bacteriology and mycology.4th Edn. p. 150.
Cho, Y., \& Yoon, K. J. (2014). An overview of calf diarrheainfectious etiology, diagnosis, and intervention. J. Vet. Sci., 15(1), 1-17.

Cho, Y., Kim, W., Liu, S., Kinyon, J. M., \& Yoon, K. J. (2010). Development of a panel of multiplex real-time polymerase chain reaction assays for simultaneous detection of major agents causing calf diarrhea in feces. J. Vet. Diagn. Invest., 22, 509-17.

Constable, P. D. (2004). Review: antimicrobial use in the treatment of calf diarrhea. J. Vet. Intern. Med., 18, 8-17.

El-Shehedi, M. A., Eraqi, M. M., \& Ali, A. R. (2013). Characterization of Escherichia coli from diarrheic calves with special reference to plasmid profile. J. Am. Sci., 9, 7.

Gay, C. C., Mckay, K. A., \& Barnum, D. A. (1964). Studies on colibacillosis of calves. II. A clinical evaluation of the efficiency of vaccination of the dam as a means of preventing colibacillosis of the calf. Can. Vet. J., 5, 297-308.

Groutides, C. P., \& Michell, A. R. (1990). Changes in plasma composition in calves surviving or dying from diarrhoea. Brit. Vet. J., 146(3), 205-210.

Gruenberg, W. (2014). Overview of Coli-septicemia. Merck Manual, April 2014.

Gunn, A. (2003). Calf Scours in Southern Australian Beef Enterprises. Animal Health and Welfare, October, 2003.

Haggag, Y. N., \& Khaliel S. A. (2002). Public health importance of certain bacteria isolated from calves and small ruminants. 2nd Vet. Cong, Faculty of Veterinary Medicine, Minufiya University, Egypt, 2(1), 173-84.

Health Management and disease (HMD). (2010). Colibacillosis. Last updated $08 \quad$ November, 2010. https://www.daf.qld.gov.au/animal-industries/dairy/healthmanagement-and diseases/colibacillosis.

Hemashenpagam, N., Kiruthiga, B., Selvaraj, T., \& Panneerselvam, A. (2009). Isolation, identification and characterization of bacterial pathogens causing calf diarrhea with special reference to Escherichia coli. Internat. J. Microbiol., 7, 2.

Hudson, D., \& White, R. G. (1982). Calf Scours Causes: Prevention and Treatment, G75-269-A, Revised November 1982.

Izzo, M. M., Kirkland, P. D., Mohler, V. L., Perkins, N. R., Gunna, A. A., \& House, J. K. (2011). Prevalence of major enteric pathogens in Australian dairy calves with diarrhea. Aust. Vet. J., 89(5), 167-73.

Joon, D. S., \& Kaura, Y. K. (1993). Isolation and characterization of same of the enterobacteria from diarrhoeic and nondiarrhoeic calves. Ind. J. Anim. Sci., 63, 373-83.

Kaper, J. B., Nataro, J. P., \& Mobley, H. L. (2004). Pathogenic Escherichia coli. Nat. Rev. Microbiol., 2(2), 123-140.

Khan, A., \& Khan, M. (1997). Bacteria isolated from natural cases of buffalo and bovine neonatal calf diarrhea, pneumonia and pneumo-enteritis. Vet. Arch., 67, 4, 161-7.

Linton, K. B. (1960). The colicine typing of coliform bacillae in the study of cross infection in urology. J. Clin. Pathol., 13, 168-172.

Lutful, K. S. M. (2010). Avian Colibacillosis and Salmonellosis: A Closer Look at Epidemiology, Pathogenesis, Diagnosis, Control and Public Health Concerns. Int. J. Environ. Res. Public Health, 7(1), 89-114.

Nolan, L. (2013). Overview of Colibacillosis in Poultry. The Merck Veterinary Manual. Merck Manuals. http://www.msdvetmanual.com/poultry/colibacillosis/overviewof-colibacillosis-in-poultry.

Oporto, B., Esteban, J. I., Aduriz, G., \&Juste, R. A. (2008). Hurtado A. Escherichia coli O157:H7 and non- O157 Shiga 
toxin-producing $E$. coli in healthy cattle, sheep and swine herds in Northern Spain. Zoon. Pub. Health, 52, 411-550.

Osman, K. M., Mustafa, A. M., Elhariri, M., \& Abdelhamed, G. S. (2013). The distribution of Escherichia coli serovars, virulence genes, gene association and combinations and virulence genes encoding serotypes in pathogenic E. coli recovered from diarrhoeic calves, sheep and goat. Transbound Emerg Dis., 60(1), 69-78.

Parr, L. W., EL-Shawi, N. N., \& Robbins, M. L. (1960). Colicine susceptibility patterns of enteropathogenic Escherichia coli. J. Bacteriol., 80, 417-418.

Pourtaghi, H., Dahpahlavan, V., \& Momtaz, H. (2013). Virulence genes in Escherichia coli isolated from calves with diarrhea in Iran. Comp. Clin. Pathol., 22, 513-15.

Radostits, O. M., Gay, C. C., Blood, D. C., \& Hinchcliff, K. W. (2000). Veterinary Medicine: A Textbook of the Diseases of Cattle, Sheep, Pigs, Goats and Horses. WB Saunders, New York, USA.

Singh, D. D., Kumar, M., Choudhary, P. K., \& Singh, H. N. (2009). Neonatal calf mortality-an overview. Intas Polivet, 10(2), 165169.

Smith, T. (1925). Focal interstitial nephritis in the calf following interference with the normal intake of colostrum. J. Exp. Med., 41, 413-425.
Smith, T., \& Little, R. B. (1930). The immunological significance of colostrum. II. The initial feeding of serum from normal cows and cows immunized towards B. coli in place of colostrum. J. Exp. Med., 51, 483-492.

Steiner, L., Busato, A., Burnens, A., \& Gaillard, C. (1997). Frequency and etiology of calf losses and calf diseases before weaning in cow-calf farms. II. Microbiological and parasitological diagnoses in diarrheic calves. DTW. Deutsche tierarztliche Wochenschrift, 104(5), 169-173.

Valdivia-Andy, G., Rosales, C., Soriano-becerrili, D. M., AlbaHurtado, F., Montaraz-Crespo, J A., \& Tortora-Prez, J. L. (2000). Interaction of $E$. coliverocytotoxin strains and rotavirus in outbreak of calf's diarrhoea. Vet. Mex., 31, 293-300.

Viring, S., Olsson, S. O., Alenius, S., Emanuelsson, U., Jacobsson, S. O., Larsson, B., ... \& Uggla, A. (1992). Studies of enteric pathogens and gamma-globulin levels of neonatal calves in Sweden. Acta Veterinaria Scandinavica, 34(3), 271 279.

Wray, C., \& Morris, J. A. (1985). Aspects of colibacillosis in farm animals. Journal of hygiene, 95(03), 577-593. 